\title{
Conformational Analysis in 18-Membered Macrolactones Based on Molecular Modeling
}

\author{
Salah Belaidi and Dalal Harkati \\ Department of chemistry, Faculty of sciences, University of Biskra, BP 145, 07000 Biskra, Algeria \\ Correspondence should be addressed to Salah Belaidi, salah_belaidi@hotmail.com \\ Received 30 January 2011; Accepted 9 March 2011 \\ Academic Editor: H. Wakamatsu
}

Copyright (๑) 2011 S. Belaidi and D. Harkati. This is an open access article distributed under the Creative Commons Attribution License, which permits unrestricted use, distribution, and reproduction in any medium, provided the original work is properly cited.

Conformational analysis of 18-ring membered macrolactones has been carried out using molecular mechanics calculations and molecular dynamics. A high conformational flexibility of macrolactones was obtained, and an important stereoselectivity was observed for the complexed macrolides. For $18 \mathrm{~d}$ macrolactone, which was presented by a most favored conformer with $20.1 \%$ without complex, it was populated with $50.1 \%$ in presence of $\mathrm{Fe}(\mathrm{CO})_{3}$.

\section{Introduction}

Macrolide antibiotics have been the focus of widespread research due to increasing bacterial resistance $[1,2]$. There have been significant synthetic and theoretical efforts to generate new core structures to address this challenge [3].

Structure elucidation of a large number of obtained molecules [4], shows the existence of two parts. The first one is a macrocyclic system from 12 to 40 links with several asymmetric centers and lactone function; the second is a sugar part. The two main classes of these macrolides are presented by two molecules; the first is erythromycin A which is an active antibiotic against a large number of bacteria, and the second is amphotericin $\mathrm{B}$ which presents a strong antifungal.

Still and Galynker [5] have shown that conformational properties of middle and large size ( 8 to 14 atoms) might induce a diastereoselection phenomenon for the reactions carried out on these compounds. More precisely, macrocycles which have a double bond $(\mathrm{C}=\mathrm{C}, \mathrm{C}=\mathrm{O})$ and correctly situated substitutes adopt privileged conformations.

Peripheral attack of the reactive by the less hindered face of $\pi$-system conduct to a higher stereoselective formation of a new asymmetric center.

Grée et al. [6] have shown also in some cases the possibility of a stereochemical control induced by tricarbonyliron.
So, our objective is to verify if this notion can be extended for cycles with large size.

In this paper, we propose to study the 18 -membered $\alpha$, $\beta$-unsaturated macrocycle in order to determine the most favored conformations and the influence of $\mathrm{Fe}(\mathrm{CO})_{3}$ on conformational flexibility of these macrocycles.

\section{Computational Procedures}

In our study, the main method of calculation, which we have used, is molecular mechanics. This is considered as the most appropriate method for larger molecules [7]. Programs that we have used are based on Allinger force field [8].

This method for structure determination includes a quantum mechanical (VESCF) $\pi$-system calculation in the iterative sequence. They use Metropolis algorithm [9].

We also used the molecular dynamics (HyperChem) for the conformational research, with following options: $1000^{\circ} \mathrm{K}$, in vacuo, step size: $0.001 \mathrm{ps}$, and relaxation time: $0.1 \mathrm{ps}$.

These calculations were carried out with two software packages: HyperChem (8.01) [10], for geometry optimization, and conformational search and Chem3D (8.0) [11], for structural representation. 
TABLE 1: Energetic difference and Boltzmann population for different conformationels types.

\begin{tabular}{|c|c|c|c|c|c|c|}
\hline \multirow{2}{*}{ Macrolactone } & \multicolumn{3}{|c|}{18 symmetric $\left(n_{1}=n_{2}=5\right)$} & \multicolumn{3}{|c|}{1818 dissymmetric $\left(n_{1}=4, n_{2}=6\right)$} \\
\hline & Type & $\Delta E$ & $\%$ & Type & $\Delta E$ & $\%$ \\
\hline \multirow{3}{*}{ To $1 \mathrm{kcal} / \mathrm{mol}$} & 5 & 0.00 & 17.2 & 6 & 0.00 & 20.1 \\
\hline & 3 & 0.58 & 15.0 & 4 & 0.37 & 18.3 \\
\hline & 4 & 0.84 & 14.1 & 3 & 0.90 & 16.1 \\
\hline \multirow{3}{*}{ To $2 \mathrm{kcal} / \mathrm{mol}$} & 6 & 1.07 & 13.3 & 8 & 1.90 & 12.6 \\
\hline & 1 & 1.89 & 10.9 & & & \\
\hline & 8 & 1.90 & 10.9 & & & \\
\hline \multirow{4}{*}{ Sup to $2 \mathrm{kcal} / \mathrm{mol}$} & 7 & 2.06 & 10.5 & 5 & 3.03 & 9.6 \\
\hline & 2 & 3.05 & 08.2 & 1 & 3.61 & 8.3 \\
\hline & & & & 7 & 3.66 & 8.2 \\
\hline & & & & 2 & 4.54 & 6.7 \\
\hline
\end{tabular}

$\Delta E$ : Energetic difference to the absolute minimum, \%: Boltzmann population.

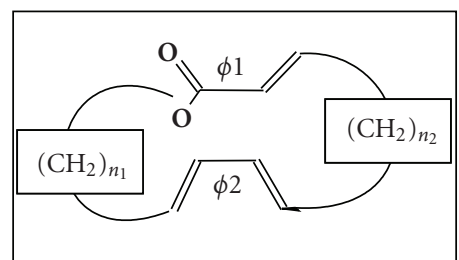

Figure 1: $\alpha, \beta$-unsaturated macrolactone.

Then, our objective is to search the favored conformations, on the basis of energy and geometric considerations with statistical calculations using Boltzmann distribution [12].

In this part of our work, we have undertaken a conformational study of macrocycle 18 (Figure 1), symmetrical which we will design $18 \mathrm{~s}\left(n_{1}=n_{2}=5\right)$, dissymmetrical which we will design $18 \mathrm{~d}\left(n_{1}=4, n_{2}=6\right)$, which represent the core group for many antibiotics.

We will also try to evaluate the stereoselectivity of addition reactions carried out on functional groups appended to the tricarbonyliron moiety.

\section{Results and Discussion}

The most stable structures can be characterized by three structural characters: the diene group, the $\alpha, \beta$-unsaturated ester group, and the two saturated chains. Thus, we have obtained eight types of conformations which are present in the majority of cases in a $6 \mathrm{kcal} / \mathrm{mol}$ energy range above the global minimum. The conformation types are classed from 1 to $8[13-15]$.

For types $(2,4,6,8)$, the two planes of two conformational sites diene and $\alpha, \beta$-unsaturated ester group were pseudoparallels; but for types $(1,3,5,7)$, the two planes of the two sites are pseudoantiparallelsure (Figure 2).

We remark also that for two conformations which we distinguish by the arrangement between the two sites, the dipole moment values are higher for pseudoparallel arrangement and lower in the opposite case (for the macrocycle $18 \mathrm{~s}$ $\mu(\mathrm{T} 2)=2.17 \mathrm{D}$ and $\mu(\mathrm{T} 1)=1.97 \mathrm{D})$.

In $1 \mathrm{kcal} / \mathrm{mol}$ difference, the macrocycle $18 \mathrm{~d}$ is characterized by the first conformer type 6 , which is the most favored with $20.1 \%$ rate followed by a type 4 with $18.3 \%$. Then, the macrocycle $18 \mathrm{~s}$ is presented preferably in the type T5 (17.2\%) and type T3 (15.0\%).

The percentages of other conformation types are listed in Table 1. The conformer populations of macrocycle $18 \mathrm{~d}$ are lightly greater than these of macrocycle 18s. For the most favored conformer geometry, the $\alpha, \beta$-unsaturated ester group has $s$-cis conformation with an angle $\phi_{1}$ : O19$\mathrm{C} 2-\mathrm{C} 3-\mathrm{C} 4=14.5^{\circ}$ for macrocycle $18 \mathrm{~d}$ and $\phi_{1}$ : O19-C2$\mathrm{C} 3-\mathrm{C} 4=25.0^{\circ}$ for cycle $18 \mathrm{~s}$.

The diene group has s-trans conformation with a torsion angle $\phi_{2}$ : C11-C12-C13-C14 $=169.4^{\circ}$ for $18 \mathrm{~d}$ and $\phi_{2}$ : C10$\mathrm{C} 11-\mathrm{C} 12-\mathrm{C} 13=179.5^{\circ}$ for $18 \mathrm{~s}$. The two systems ester and diene are parallel between themselves. These macrocycles have a very high conformational flexibility.

However, mobility of dissymmetric macrocycles is lightly less important than that of symmetric macrocycles.

They present many privileged conformations that do not a priori foresee a diastereoselection for envisaged reactions. This is in agreement with Still's works, on macrocycle 17, which yields many different conformations [16].

We have studied also the exerted effect by tricarbonyliron on conformational flexibility of these macrocycles. We note that organometallic complex can intervene by a very high steric hindrance and also introducing an important rigidification of skeleton. The results of conformational analysis of two complexed macrocycles 18 show that tricarbonyliron has a considerable influence on cycles, because the number of possible conformations was reduced to four types [17-19].

In $1 \mathrm{kcal} / \mathrm{mol}$ energetic difference, the complexed macrocycle 18 s shows three favored conformations and only one favored conformation for $18 \mathrm{~d}$.

The peopling rate of the most stable conformers was increased for complexed macrocycles compared with these without tricarbonyliron (Table 2). 

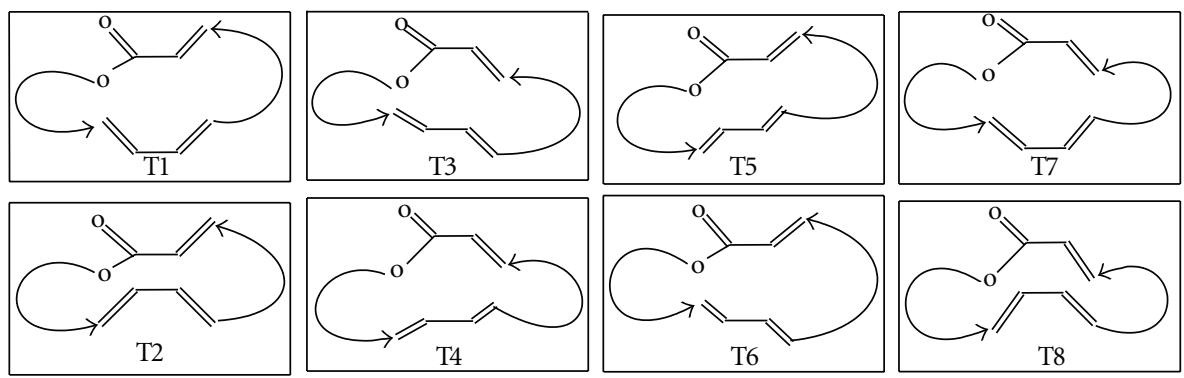

Figure 2: Main conformational types.

TABLE 2: Energetic difference and Boltzmann population of different conformational types of complexed macrocycles.

\begin{tabular}{|c|c|c|c|c|c|c|}
\hline \multirow{2}{*}{ Macrolactone } & \multicolumn{3}{|c|}{18 symmetric $\left(n_{1}=n_{2}=5\right)$} & \multicolumn{3}{|c|}{18 dissymmetric $\left(n_{1}=4, n_{2}=6\right)$} \\
\hline & Type & $\Delta E$ & $\%$ & Type & $\Delta E$ & $\%$ \\
\hline \multirow{3}{*}{ to $1 \mathrm{kcal} / \mathrm{mol}$} & 1 & 0.00 & 28.5 & 8 & 0.00 & 50.1 \\
\hline & 8 & 0.30 & 26.5 & & & \\
\hline & 7 & 0.54 & 25.1 & & & \\
\hline \multirow{3}{*}{ Sup to $1 \mathrm{kcal} / \mathrm{mol}$} & 2 & 1.47 & 19.9 & 7 & 4.04 & 18.8 \\
\hline & & & & 1 & 4.30 & 17.6 \\
\hline & & & & 2 & 5.39 & 13.5 \\
\hline
\end{tabular}

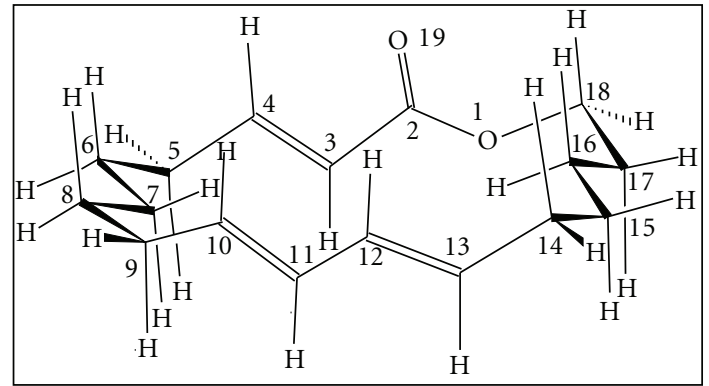

(a)

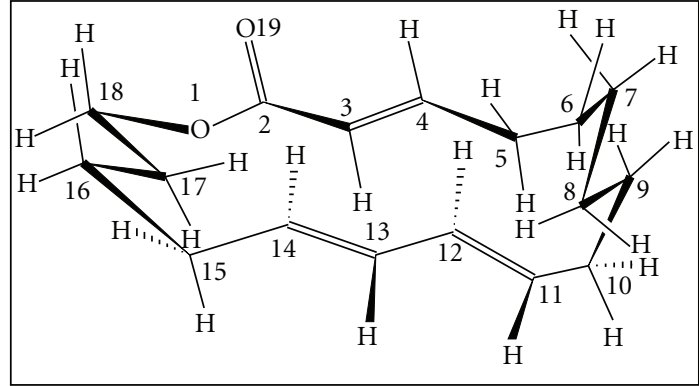

(b)

Figure 3: Most favored conformers of macrocycles $18 \mathrm{~s}$ (a) and 18d (b).

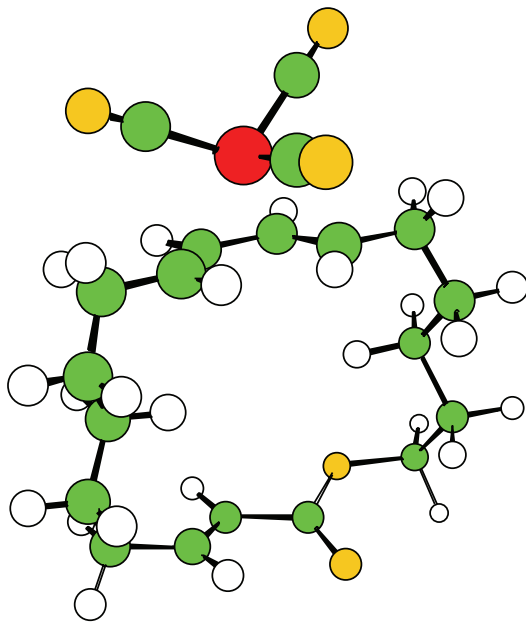

(a)

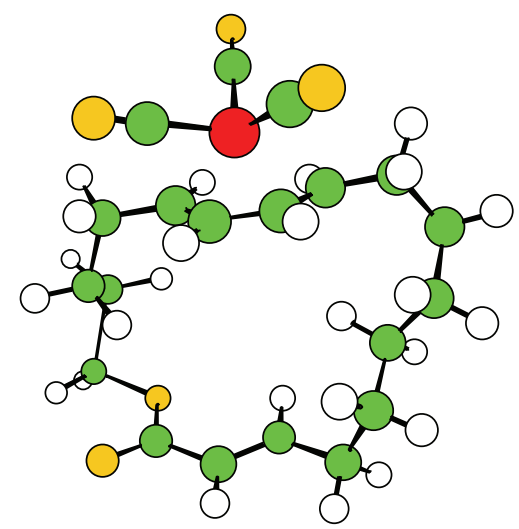

(b)

FIgURE 4: Most favored conformers of complexed macrocycles 18s (a) and 18d (b). 
For macrocycle $18 \mathrm{~d}$, which was presented by a preferred conformer with $20.1 \%$ without complex, it was populated with $50.1 \%$ in presence of $\mathrm{Fe}(\mathrm{CO})_{3}$.

We remark also that macrocycles 18 s and $18 \mathrm{~d}$ were presented, respectively, in T1 type with $28.5 \%$ and T8 type with $50.1 \%$ for the most favored conformers.

Dienic system was fixed in s-cis conformation for all preferential conformations. The dihedral angle value of dienic system was comprised between 1.0 and $5.4^{\circ}$ for 18 s cycle and between 4.1 and $13.9^{\circ}$ for $18 \mathrm{~d}$ cycle. The lower deviations of registered dihedral angles compared with normal values were imposed essentially by a cyclic chain [20].

The presence of tricarbonyliron motif imposes a minimum steric modifications and introduces an asymmetric element. So, this creates a favorable environment to discrimination between two faces of macrocycles increasing thus a peripheral attack proportion (Figure 4).

This reasoning was found again in methyl acetates with fluorine containing auxiliaries where intramolecular interaction Li-F creates a steric hindrance around one of two faces causing a diastereofacial selectivity of 94.6:5.4 [21]. The lactone function and complexed diene were practically perpendicular at medium plane of the cycle.

This is in agreement with Still's works that affirm that $\mathrm{CH}_{3} \mathrm{I}$ addition will be executed on the clear face by peripheral attack [5]. The study carried out by Cox and Ley [22], on $\mathrm{Fe}(\mathrm{CO})_{3}$ complexes has shown that the presence of complex, which has an important steric effect, induced a diastereoselectivity in addition reactions (Figure 3 ).

\section{Conclusion}

We conclude that our study shows the existence of a very high conformational flexibility increasing in a majority of noncomplexed macrolactones.

Finally, the obtained diastereoselectivity for complexed macrolactones is the result of the stereochemical control effect of the tricarbonyliron. It has introduced an asymmetric element, an important steric effect increasing a peripheral attack proportion, and has contributed to the rigidity of the structure. This last factor constitutes a tool of the stereochemical remote control, which permits us to foresee a priori the phenomenon of the stereoselectivity for alkylation reactions.

\section{References}

[1] K. Warabi, D. E. Williams, B. O. Patrick, M. Roberge, and R. J. Andersen, "Spirastrellolide B reveals the absolute configuration of the spirastrellolide macrolide core," Journal of the American Chemical Society, vol. 129, no. 3, pp. 508-509, 2007.

[2] T. Hosoe, K. Fukushima, K. Takizawa et al., "A new antifungal macrolide, eushearilide, isolated from Eupenicillium shearii," Journal of Antibiotics, vol. 59, no. 9, pp. 597-600, 2006.

[3] B. C. Raimundo and C. H. Heathcock, "Synthesis of a model for C7-C13 of lankamycin,” Organic Letters, vol. 2, no. 1, pp. 27-28, 2000.

[4] A. Nakagawa and S. Omura, "Structure and stereochemistry of macrolides," in Macrolide Antibiotics, Chemistry, Biology and Practice, pp. 37-84, Academic Press, New York, NY, USA, 1984.

[5] W. C. Still and I. Galynker, "Chemical consequences of conformation in macrocyclic compounds : an effective approach to remote asymmetric induction," Tetrahedron, vol. 37, no. 23, pp. 3981-3996, 1981.

[6] D. M. Grée, C. J. M. Kermarrec, J. T. Martelli, R. L. Grée, J. P. Lellouche, and L. J. Toupet, "The first enantiocontrolled synthesis of E,E conjugated dienes with a fluorine atom in the allylic position," Journal of Organic Chemistry, vol. 61, no. 6, pp. 1918-1919, 1996.

[7] O. Becker, A. D. MacKerell, J. B. Roux, and M. Watanabe, Eds., Computational Biochemistry and Biophysics, Marcel Dekker Inc., New York, NY, 2001.

[8] N. L. Allinger, "Conformational analysis. 130. MM2. A hydrocarbon force field utilizing V and V torsional terms," Journal of the American Chemical Society, vol. 99, no. 25, pp. 8127-8134, 1977.

[9] N. Metropolis, A. W. Rosenbluth, M. N. Rosenbluth, A. H. Teller, and E. Teller, "Equation of state calculations by fast computing machines," The Journal of Chemical Physics, vol. 21, no. 6, pp. 1087-1092, 1953.

[10] C.S. Chem 3D Pro, "Molecular Modeling and Analysis," Cambridge Soft Corporation, 875 Massachusetts, 02139 U.S.A, 2005.

[11] HyperChem (Molecular Modeling System) Hypercube, Inc., 1115 NW 4th Street, Gainesville, FL32601; USA, 2005.

[12] J. Koča, "Potential energy hypersurface and molecular flexibility," Journal of Molecular Structure, vol. 291, no. 2-3, pp. 255269, 1993.

[13] S. Belaidi, A. Dibi, and M. Omari, "A conformational exploration of dissymmetric macrolides antibiotics," Turkish Journal of Chemistry, vol. 26, no. 4, pp. 491-500, 2002.

[14] S. Belaidi, M. Laabassi, R. Grée, and A. Botrel, "Analyse multiconformationnelle des macrolides symétriques de 12 à 28 chaînons basée sur la mécanique moléculaire," Scientific Study \& Research, vol. 4, pp. 27-38, 2003.

[15] S. Belaidi, T. Lanez, M. Omari, and A. Botrel, "Quantitative conformational analysis of dissymmetric macrolides by molecular modelling," Asian Journal of Chemistry, vol. 17, no. 2, pp. 859-870, 2005.

[16] M. Saunders, K. N. Houk, Y. D. Wu et al., "Conformations of cycloheptadecane. A comparison of methods for conformational searching," Journal of the American Chemical Society, vol. 112, no. 4, pp. 1419-1427, 1990.

[17] S. Belaidi, M. Omari, T. Lanez, and A. Dibi, " Contribution à l'étude de la relation structure-activité dans des nouveaux macrolides antibiotiques," Journal de La Société Algérienne de Chimie, vol. 14, pp. 27-39, 2004.

[18] S. Belaidi, M. Laabassi, R. Gree, and A. Botrel, "New approach to the stereoselectivity of macrolide antibiotics with 20 atoms chains through molecular modelizationNouvelle approche de la stérÉosélectivité dans les macrolides antibiotiques à 20 chaînons par modélisation moléculaire," Revue Roumaine de Chimie, vol. 50, no. 9-10, pp. 759-765, 2005.

[19] S. Belaidi, M. Omari, and T. Lanez, "Stereochemical analysis in 22-membered macrolides based on molecular modeling," Annales de la Faculté des Sciences et Sciences de l'Ingénieur, vol. 1 , pp. 1-4, 2006.

[20] O. Abdelmalek, S. Belaidi, M. Mellaoui, and R. Mazri, "Geometric and electronic structure of isoxazole and isothiazole derivatives by PM3 and density functional theory," Asian Journal of Chemistry, vol. 23, no. 3, pp. 1183-1185, 2011. 
[21] T. Yamazaki, M. Ando, T. Kitazume, T. Kubota, and M. Omura, "Conformational fixation of enolates by intramolecular metal - . fluorine interaction," Organic Letters, vol. 1, no. 6, pp. 905-908, 1999.

[22] L. R. Cox and S. V. Ley, "Tricarbonyliron complexes: an approach to acyclic stereocontrol," Chemical Society Reviews, vol. 27, no. 5, pp. 301-314, 1998. 


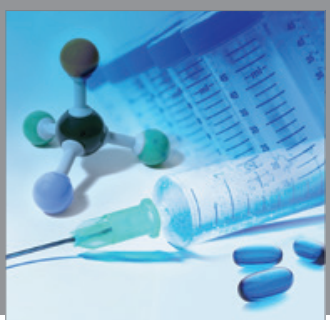

International Journal of

Medicinal Chemistry

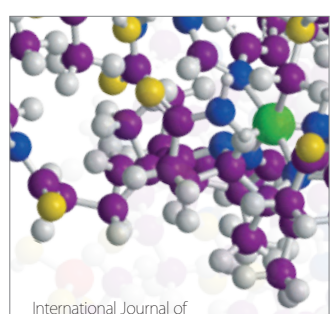

Carbohydrate Chemistry

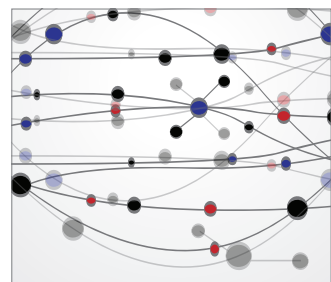

The Scientific World Journal
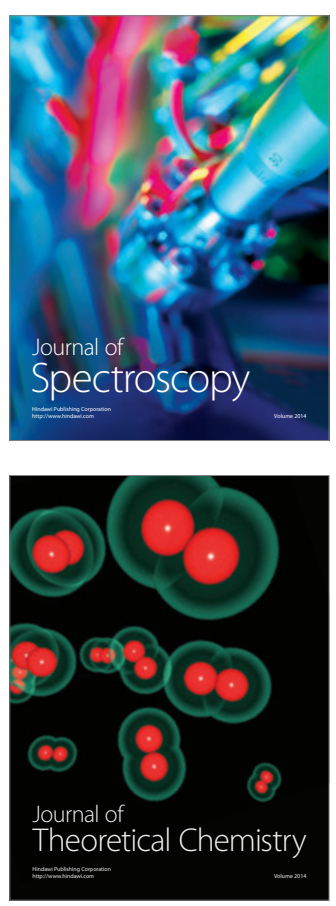
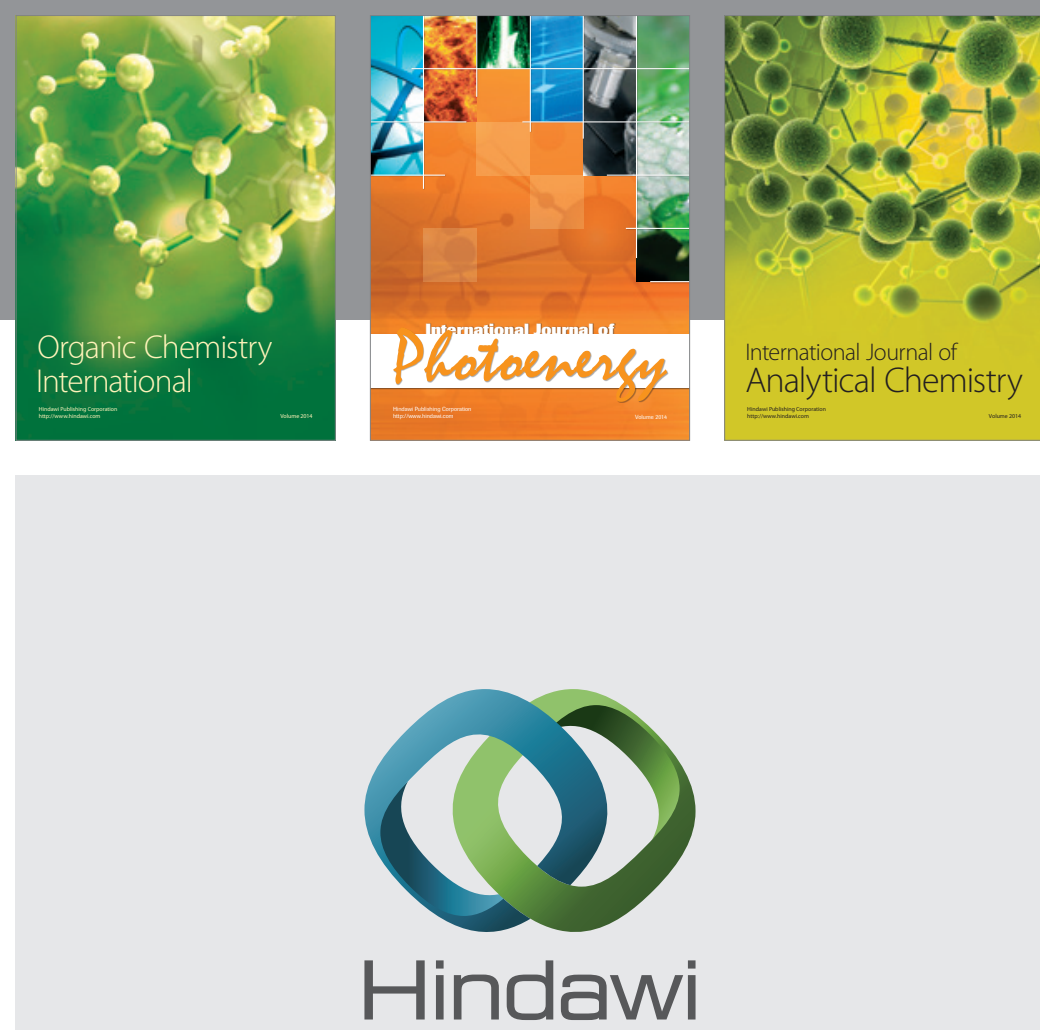

Submit your manuscripts at

http://www.hindawi.com
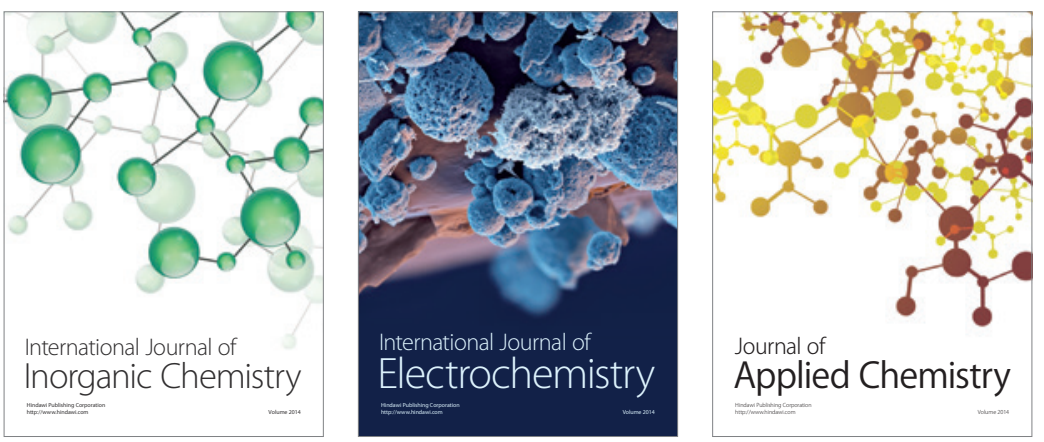

Journal of

Applied Chemistry
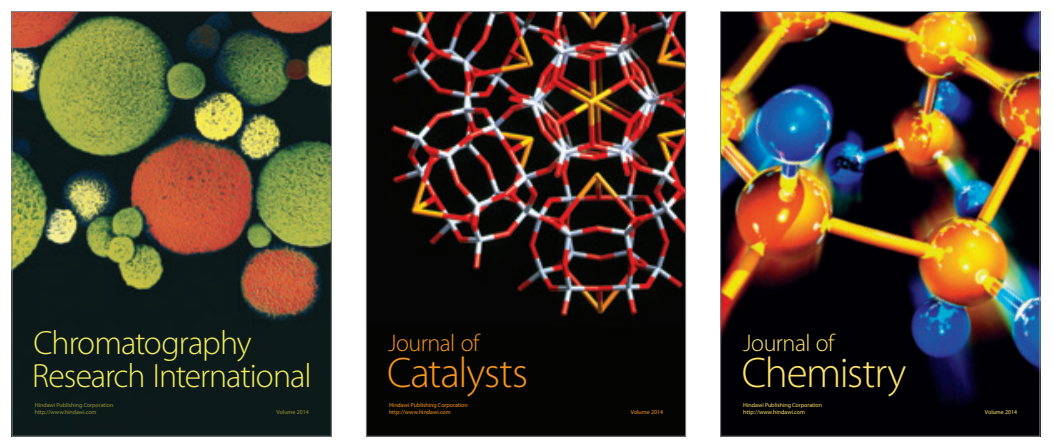
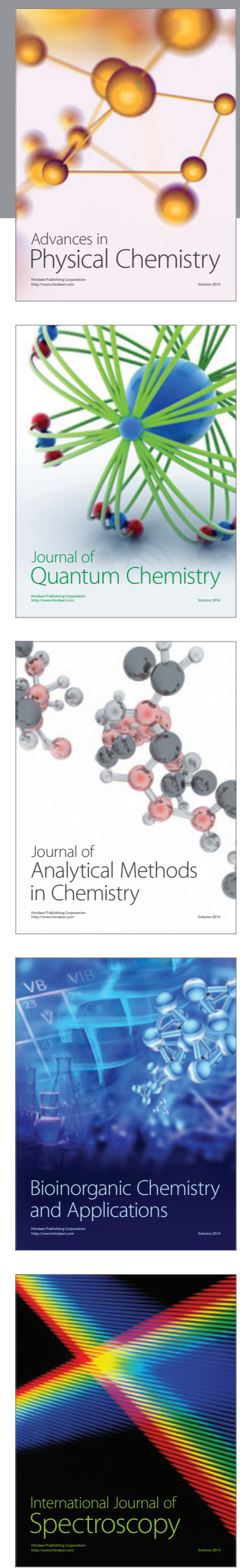